\title{
Complementary Split Ring Resonator Loaded Substrate Integrated Waveguide Leaky Wave Antenna
}

\author{
Basma M. Yousef ${ }^{1}$, Ahmed M. Attiya ${ }^{2}$, A. A. Shaalan ${ }^{3}$ \\ ${ }^{1}$ Communications Department, Delta Higher Institute for Engineering and Technology, Mansoura, Egypt \\ ${ }^{2}$ Microwave Department, Electronics Research Institute, Cairo, Egypt \\ ${ }^{3}$ Electronics and communications Department, Faculty of Engineering, Zagazig University, Zagazig, Egypt \\ Email: basmamyousef@gmail.com, attiya@eri.sci.eg, ashaalan@zu.edu.eg,shaalan_zag2010@yahoo.com
}

How to cite this paper: Yousef, B.M., Attiya, A.M. and Shaalan, A.A. (2019) Complementary Split Ring Resonator Loaded Substrate Integrated Waveguide Leaky Wave Antenna. Open Journal of Antennas and Propagation, 7, 1-11.

https://doi.org/10.4236/ojapr.2019.71001

Received: February 28, 2019

Accepted: March 26, 2019

Published: March 29, 2019

Copyright $\odot 2019$ by author(s) and Scientific Research Publishing Inc. This work is licensed under the Creative Commons Attribution International License (CC BY 4.0).

http://creativecommons.org/licenses/by/4.0/

\begin{abstract}
In this paper we present the design of a leaky wave antenna based on Substrate Integrated Waveguide (SIW) loaded by Complementary Split Ring resonator (CSRR). The proposed antenna is designed for $5 \mathrm{G}$ application with a center frequency around $28 \mathrm{GHz}$. The antenna is implemented on Roger $\mathrm{RT} /$ Duriod 5880. The loading CSRRs are designed to resonate at $28 \mathrm{GHz}$. The design is simulated by using both High-Frequency Simulation Software (HFSS) and Computer Simulation Technology (CST) for verification. Experimental measurements are also presented.
\end{abstract}

\section{Keywords}

Leaky Wave Antennas, MM-Wave, 5G, SIW Antennas

\section{Introduction}

Leaky Wave Antennas (LWAs) can be described as a fast wave guiding structure with a complex propagation constant. LWAs can be classified into two main categories [1] [2] [3]; uniform guided wave structures [4] [5], and periodic guided wave structures [6] [7] [8] [9]. The uniform leaky-wave antenna can be scanned by varying frequency and its scanning range is extended from broadside to end fire, with the beam closer to end fire at higher frequencies [3]. Different antenna configurations can be used for leaky wave applications, substrate integrated waveguides (SIW) are quite suitable for these applications [10] [11]. On the other hand, in periodic leaky wave antennas, the beam swings up from backward direction towards the broadside and then through the broadside to 
forward direction [3].

In [12], an LWA based on a periodic set of slots printed on a dielectric waveguide is introduced to obtain low side lope level (SLL). Different SIW leaky-wave antennas are proposed in [13]. The SIW long slot leaky-wave antenna is an example of SIW leaky wave antennas. In [13], a straight slot etched on the broadside of a meandering SIW exhibits SLL which can be acquired by tapering the aperture distribution of the centered slot. As the slot is designed to be symmetrical, the SIW straight long slot LWA can enhance cross-polarization level up to $30 \mathrm{~dB}$. To decrease the cross polarization, a long slot is printed on the SIW centerline, and a sinusoidal ridge is applied to create a controllable asymmetric electric field around the long slot [11].

In this paper, a periodic LWA structure based on complementary split ring resonators (CSRRs) etched on the top of an SIW is proposed. Thus, an SIW structure with an equivalent effective negative constituent meta-surface can be obtained. Tapering line sections are designed to match the designed leaky wave structure to the feeding microstrip line. On the other hand, mm-wave leaky wave antennas are good candidates for different applications like radars [14], real time spectrum analyzers [15] and 5G mobile communications [16] [17]. In addition SIW is a good technique for implementing these mm-wave leaky wave antennas. The proposed CSRR-LWA can be used to steer the main beam from backward to forward direction through broadside at different frequencies. The effective width of SIW, diameter of via holes and rings are chosen according to operating frequency range. The proposed leaky-wave antenna in this paper has a wide bandwidth from 21 to $33 \mathrm{GHz}$ with frequency steering from $-60^{\circ}$ to $60^{\circ}$. The use of CSRR introduces a large bandwidth and expands the range of frequency scanning. The gain of the proposed antenna is improved by approximately $2 \mathrm{~dB}$ compared with previously published results in [6] [9]. The size of the designed antenna is also reduced compared with these designs. The complete antenna structure is simulated by using both HFSS and CST for verification. In addition experimental measurements are presented, too.

In Sec. 2, the equivalent circuit model of a unit cell is discussed. The design simulation and experimental results of the proposed SIW leaky wave antenna are discussed in Sec. 3. Finally, Sec. 4 presents the concluding remarks.

\section{Design of the Unit Cell}

To introduce the wave leakage in the proposed SIW leaky wave antenna, periodic perturbations are added to the SIW. The proposed perturbation is CSRR as shown in Figure 1. The role of each perturbation is mainly to radiate a fraction of the guided wave. To introduce the required radiation, this CSRR should be nearly resonant at the proposed frequency of operation. In the present case, the required frequency is around $28 \mathrm{GHz}$.

In microstrip technology, a broadband negative $\mu$ media can be fabricated by using periodically etching series gaps on a microstrip transmission line 
[18]-[23]. The analysis of split ring resonator (SRR) and CSRR and their electromagnetic properties are discussed in [24]. In this analysis, SRRs and CSRRs behave as an equivalent LC resonator is excited by an external magnetic flux and electric flux respectively. Figure 1 shows the intrinsic equivalent circuit model of the CSRR. It is represented as dual of the SRR model. This equivalent circuit consists of a capacitance $C_{c}$ of a disk of radius $r_{o}-c / 2$ surrounded by a ground plane, where $r_{o}$ is the average radius of ring and $c$ is the width of the slot ring, and a parallel combination of the two inductances $L_{o} / 2$ connecting the inner disk to the ground.

An analytical approximate expression for $C_{c}$, is presented in [24]. The final expression is

$$
C_{c}=\frac{\pi^{3} \varepsilon_{o}}{c^{2}} \int_{0}^{\infty} d k \frac{[b \mathcal{B}(k b)-a \mathcal{B}(k a)]^{2}}{k^{2}}\left[\frac{1}{2}\left(1+\frac{1+\frac{\varepsilon}{\varepsilon_{o}} \tanh (k h)}{1+\frac{\varepsilon_{0}}{\varepsilon} \tanh (k h)}\right)\right]
$$

where $a=r_{o}-c / 2$ and $b=r_{o}-c / 2$ are the geometrical parameters shown in Figure 1 and the function $\mathcal{B}$ is defined as:

$$
\mathcal{B}(x)=S_{0}(x) J_{1}(x)-S_{1}(x) J_{0}(x)
$$

$S_{n}$ and $J_{n}$ being the $n^{\text {th }}$ order of Struve and Bessel functions respectively.

Each inductance of the two parallel can be considered as $L_{o} / 2$ where $h=0.508 \mathrm{~mm}$ and $L_{p u l}$ is the per unit length inductance of the CPW connecting the inner disk to the transmission line [25]. The total CSRR inductance can be calculated as $L_{c}=L_{o} / 4$. After calculating the total CSRR capacitance $C_{c}$ and inductance $L_{c}$, the resonant frequency can be obtained from Equation (3) as

$$
f_{o, C S R R}=\frac{1}{2 \pi \sqrt{l_{c} c_{c}}}
$$

Using Equations (1)-(3) the initial values for a specific resonant frequency of $a, b$ and $r_{o}$ can be obtained. The proposed unit cell is designed to operate at frequency $28 \mathrm{GHz}$. The substrate is Roger/RT Duroid 5880 (tm) with a permittivity of $\varepsilon_{r}=2.2$ and a substrate thickness $h=0.508 \mathrm{~mm}$. According to the previous steps and resonance frequency of $28 \mathrm{GHz}$, the initial values of $a, b$ and $r_{o}$ are obtained as follows $1.2 \mathrm{~mm}, 1.5 \mathrm{~mm}$ and $1.35 \mathrm{~mm}$ respectively.

These initial values are used to simulate a unit cell inserted inside periodic boundary conditions and terminated by input and output wave ports. The unit cell structure is shown in Figure 2. Figure 3 shows the scattering parameter of unit cell over the frequency range from 21 to $33 \mathrm{GHz}$. The complex propagation constant can be recovered from these transmission and reflection coefficients (S-Parameters) according to theses Equations (4-a) and (4-b) [26] [27]:

$$
\beta=\operatorname{Re}\left[\cos ^{-1}\left(\frac{1-S_{11} S_{22}+S_{12} S_{21}}{2 S_{21}}\right)\right]
$$




$$
\alpha=\operatorname{Im}\left[\cos ^{-1}\left(\frac{1-S_{11} S_{22}+S_{12} S_{21}}{2 S_{21}}\right)\right]
$$

The results of dispersion diagram for a unit cell are shown in Figure 4; Figure 4 (a) shows the real part of complex propagation constant $(\beta)$, while Figure 4 (b) shows the imaginary part of complex propagation constant (the attenuation constant $\alpha$ ) normalized to the free space propagation constant $k_{0}$.
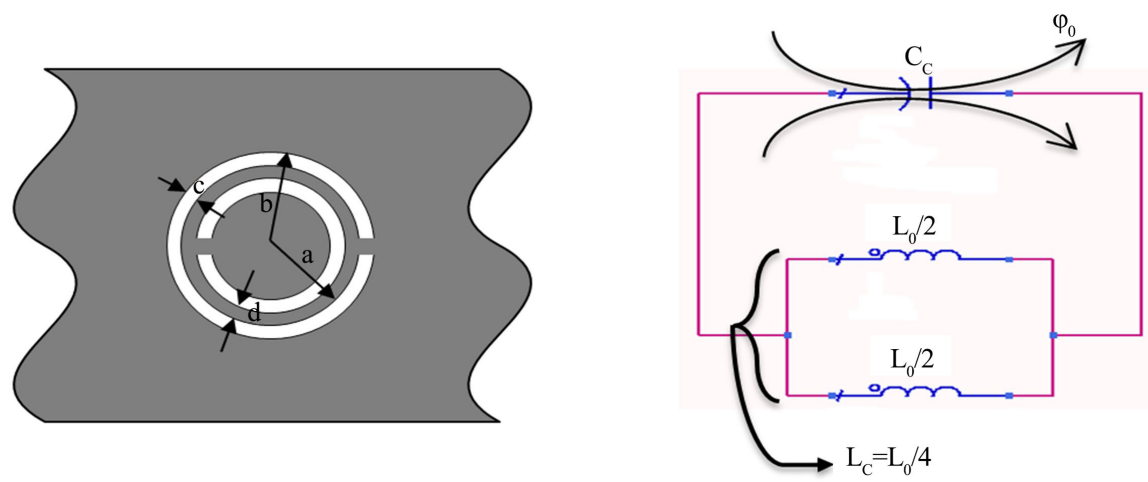

Figure 1. The intrinsic equivalent circuit model of the CSRR.

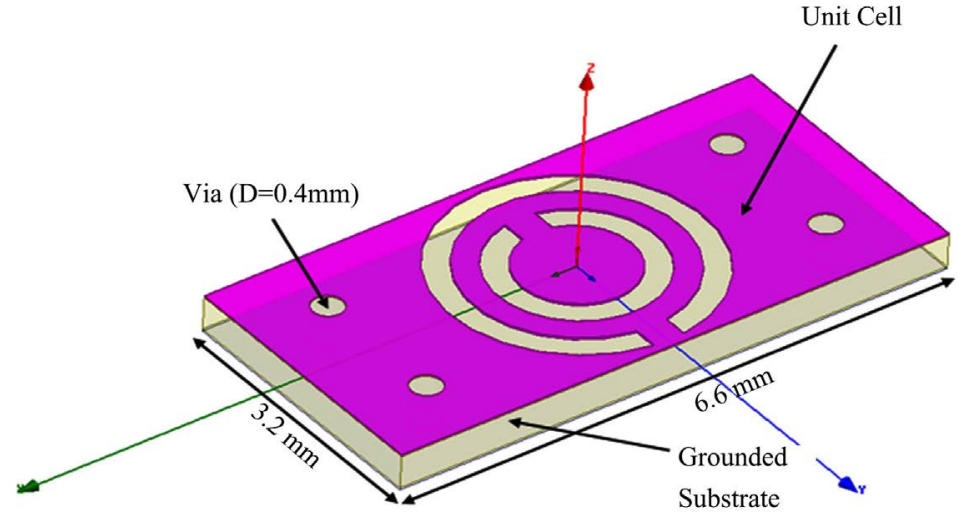

Figure 2. The unit cell structure.

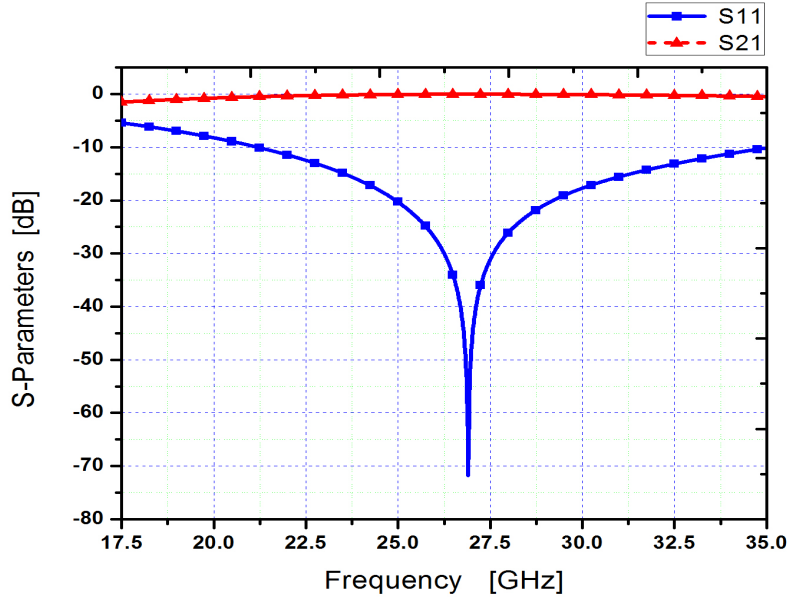

Figure 3. S-Parameters of the unit cell. 


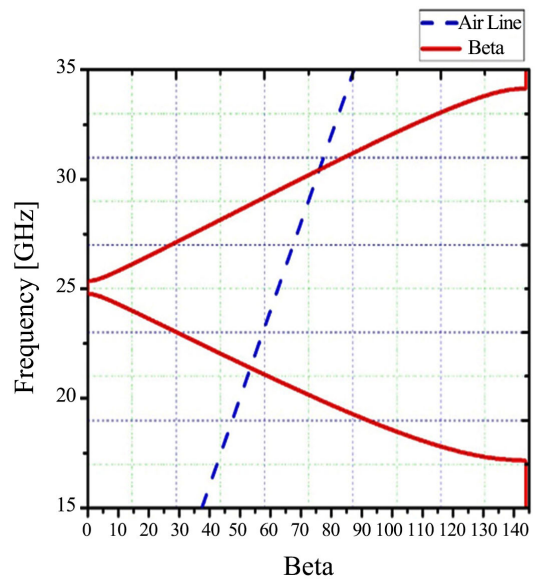

(a)

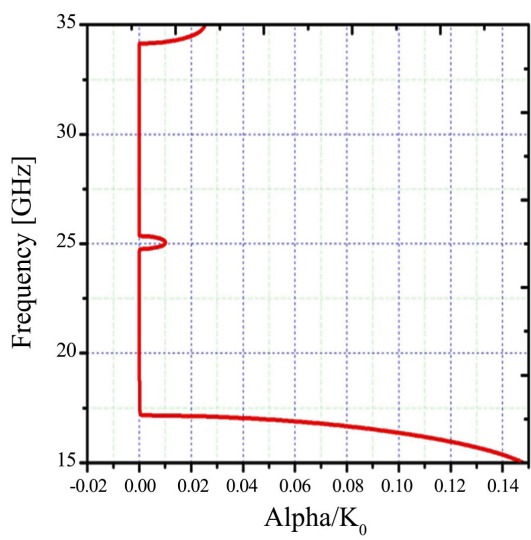

(b)

Figure 4. The results of dispersion diagram for unit-cell, (a) $\beta / \mathrm{K}_{0}$ and (b) $\alpha / \mathrm{K}_{0}$.

\section{Complete Antenna Design}

The proposed antenna is designed based on substrate integrated wave guide (SIW) consisting of two horizontal metal plates, the ground plane and the transmission line plate with etching CSRR, printed on dielectric substrate. The two metal plates are connected together by using metal vias in both sides of the substrate. These vias act as side walls of the wave guide as shown in Figure 5.

The designed leaky wave antenna consists of ten unit-cells. The separation between the adjacent unit-cells is $0.2 \mathrm{~mm}$. The overall antenna size is $6.6 \times 41.4$ $\mathrm{mm}^{2}$, which is printed on grounded Roger/RT Duroid 5880 (tm) substrate. To match the designed antenna to $50 \Omega$ feed line, the two ends of the designed antenna are terminated by tapering matching sections. Figure 6 shows a parametric study of outer radius of the CSRR $b$. The outer radius of $1.7 \mathrm{~mm}$ is the optimum one for the required application around $28 \mathrm{GHz}$. In Figure 7, a parametric study of the ring width $c$ is introduced and $0.285 \mathrm{~mm}$ is chosen to be the accepted one. The gap between the two rings is assumed to be equal the ring width. Figure 8 shows the fabricated antenna and its measurements. Figure 9 shows a comparison between the simulated and measure $S$ parameters of the designed leaky wave antennas. Good agreements between the two results are obtained. These reflection and transmission coefficients are used to determine the normalized radiated power as follows:

$$
P_{\text {rad }} / P_{i n}=1-\left|S_{11}\right|^{2}-\left|S_{21}\right|^{2}
$$

Figure 10 shows a comparison between the simulated and measured normalized radiated power as a function of the operating frequency. It can be noted that the maximum radiated power occurs at around $28 \mathrm{GHz}$, which it is expected from the results of complex propagation constant.

Figure 11 shows the radiation pattern along E-plane at the designed frequency of $28 \mathrm{GHz}$. The maximum radiation pattern can be obtained at more than one frequency. Frequency scanning from angle $-60^{\circ}$ to $60^{\circ}$ is achieved around the resonant frequency as shown in Figure 12. 
The radiation efficiency of this antenna is shown in Figure 13 which gives good efficiency.

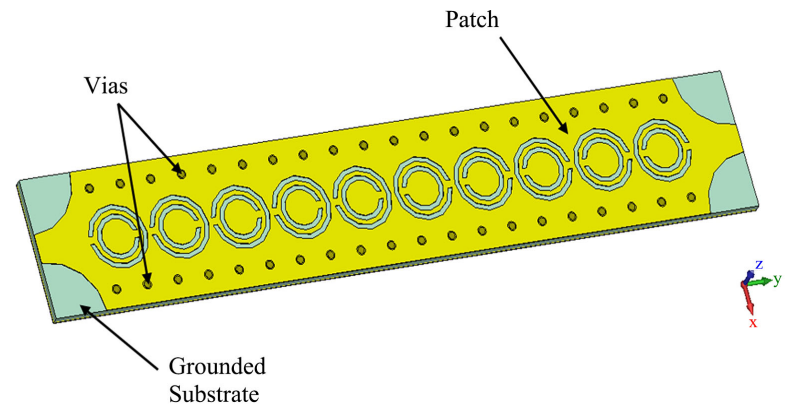

Figure 5. Leaky wave antenna of a SIW loaded by periodic CSRR.

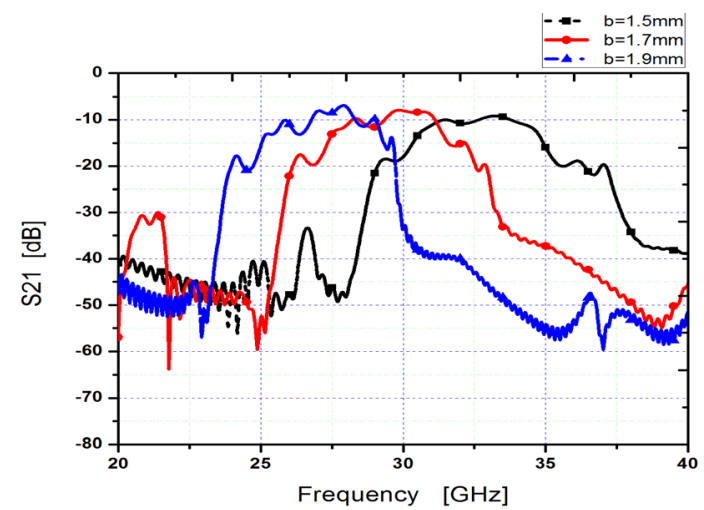

Figure 6. Parametric study of outer radius of the CSRR.

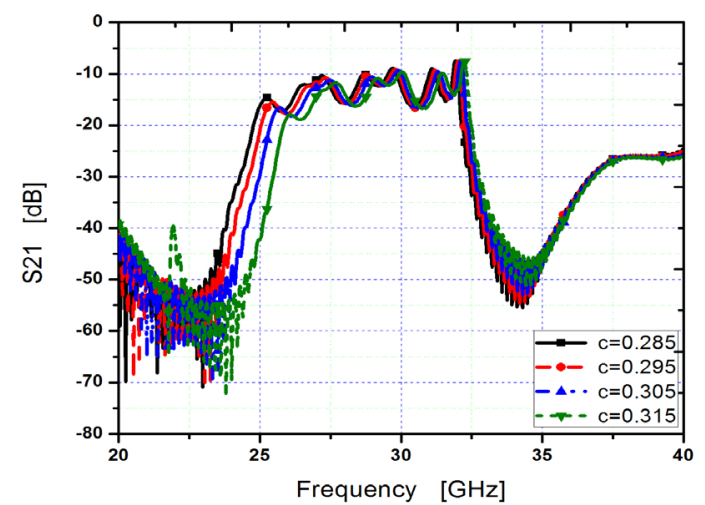

Figure 7. Parametric study of the ring width.

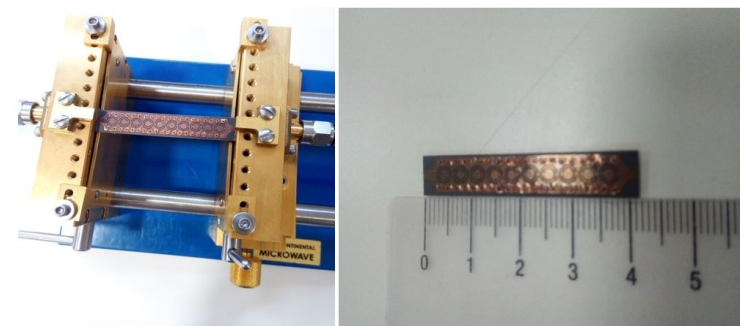

Figure 8. Fabricated Antenna. 


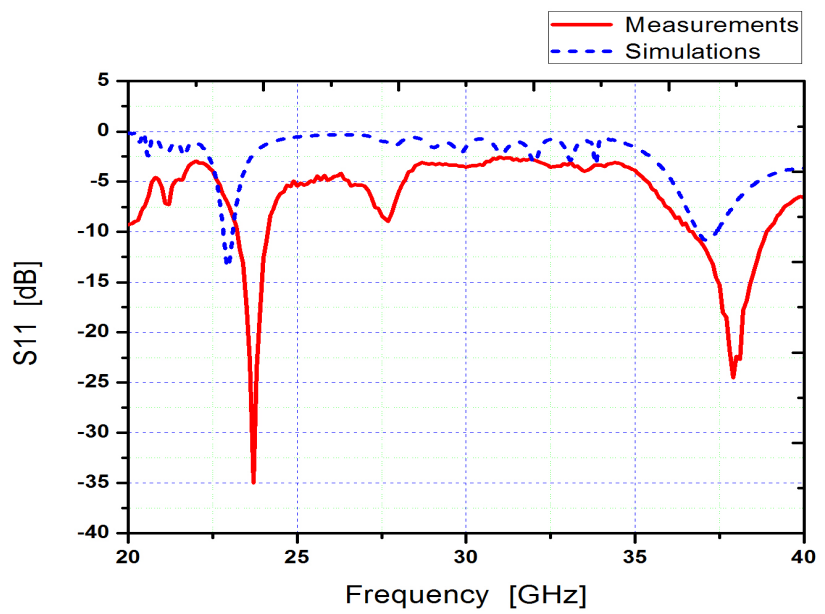

(a)

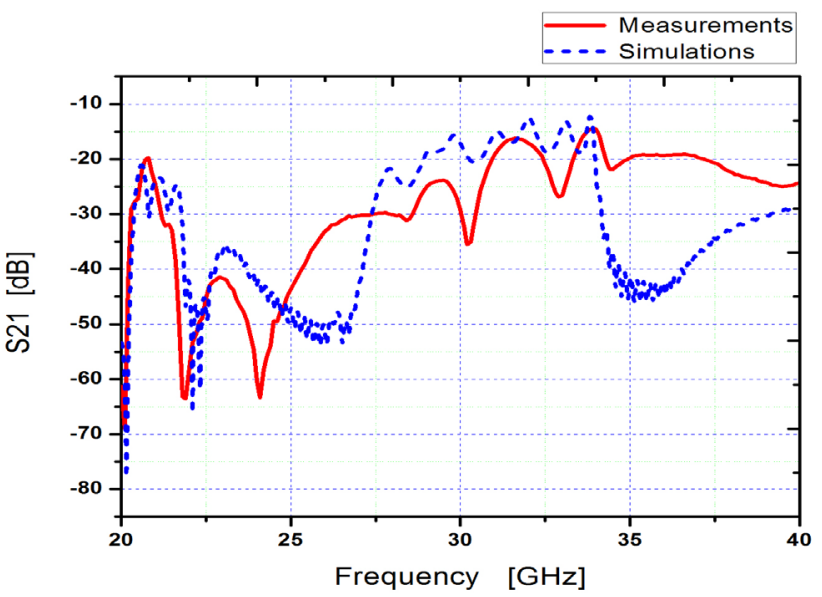

(b)

Figure 9. (a) Comparison between the simulated and measured S11 of the designed leaky wave antenna; (b) Comparison between the simulated and measured S21 of the designed leaky wave.

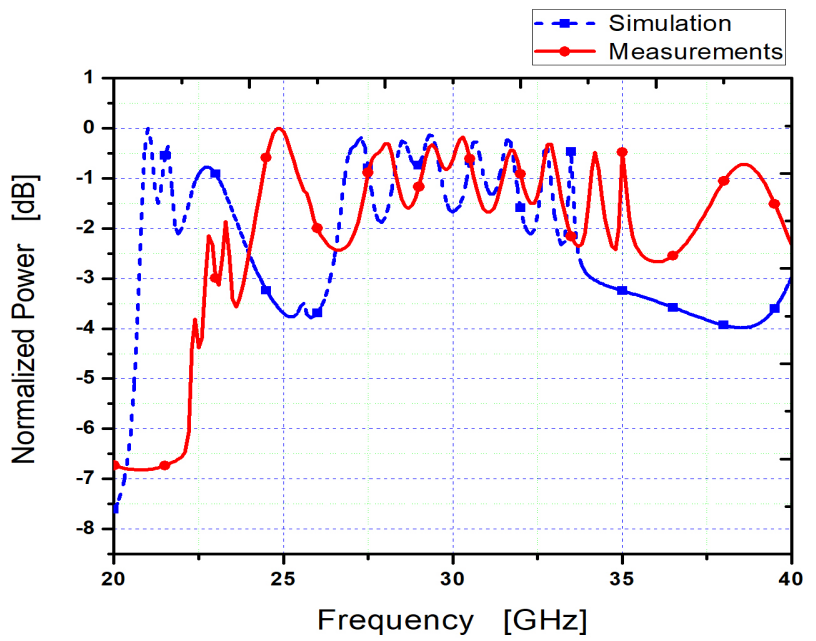

Figure 10. Comparison between the simulated and measured normalized radiated power of the designed leaky wave. 


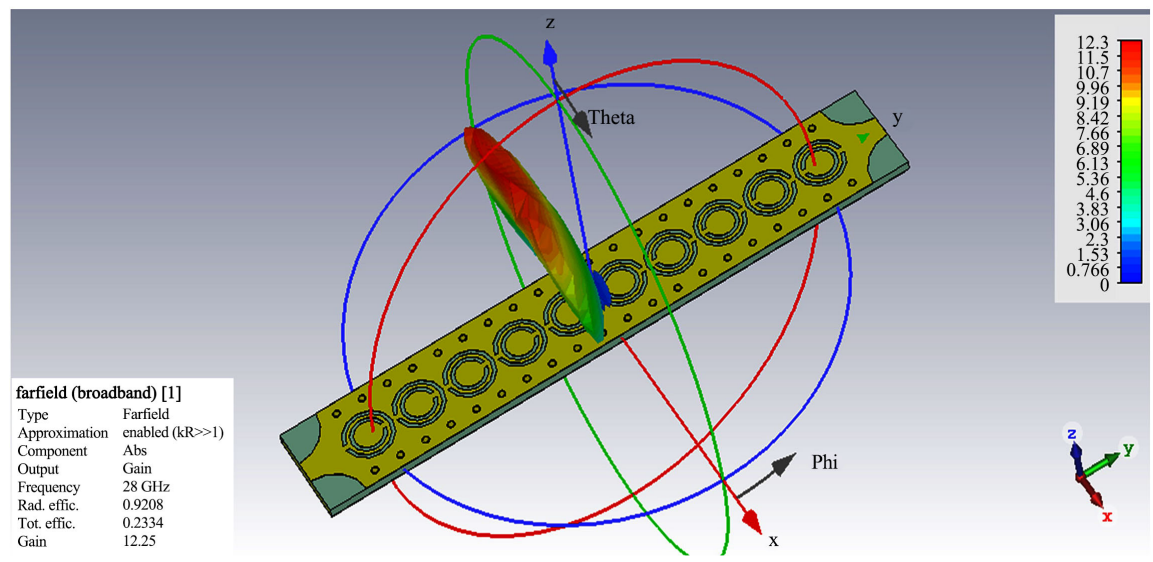

Figure 11. Radiationpattern at frequency $28 \mathrm{GHz}$.

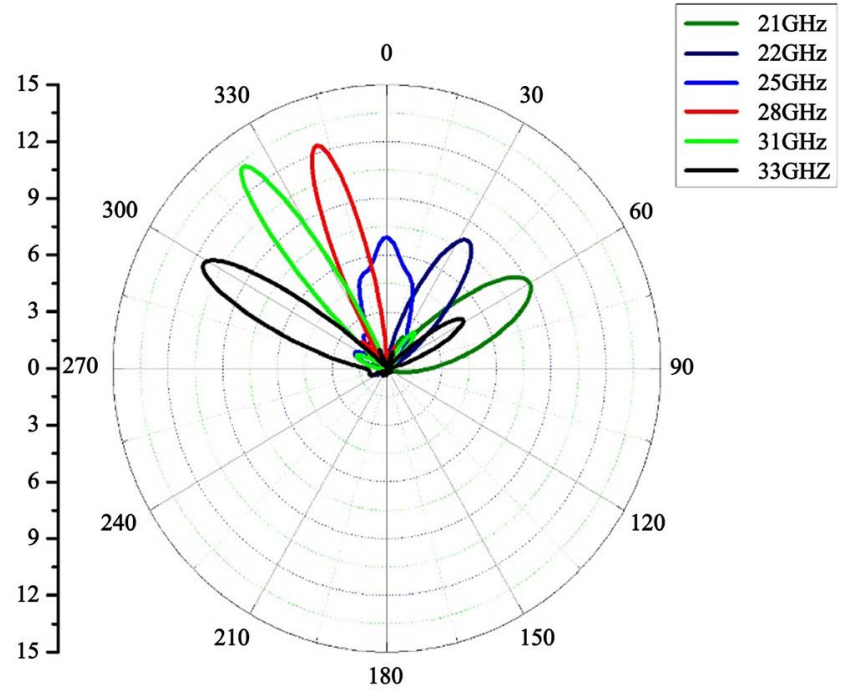

Figure 12. Frequency scanning radiation pattern.

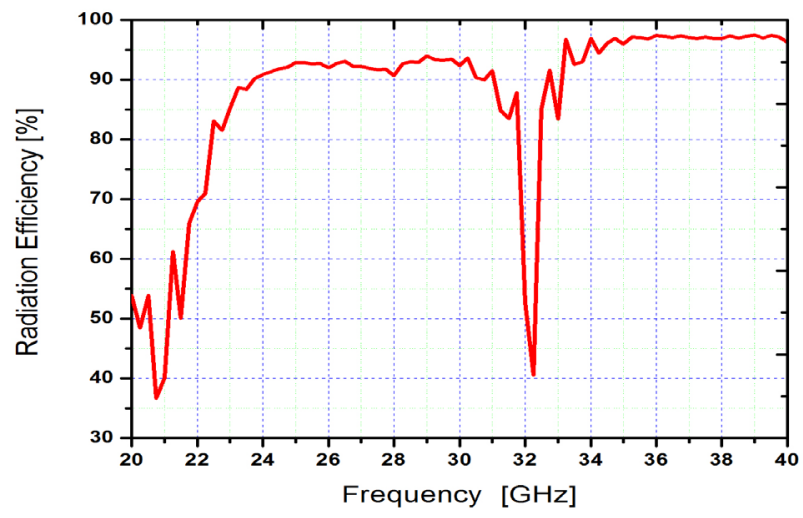

Figure 13. The radiation efficiency of the CSRR leaky wave antenna.

\section{Conclusion}

In this paper the design of a leaky wave antenna based in CSRR loaded SIW is presented. The proposed antenna is designed at a frequency $28 \mathrm{GHz}$. The ob- 
tained antenna can be used in the frequency range from 21 to $33 \mathrm{GHz}$. Frequency scanning is also obtained. This property makes the proposed antenna be suitable for scanning radar application, in addition to the proposed application of $5 \mathrm{G}$ communication. Tapering sections are used to terminate the two ends of the proposed antenna to be matched with the feeding network. Good matching is obtained by using this technique. The impedance matching, radiation pattern and radiation efficiency are studied for this antenna.

\section{Conflicts of Interest}

The authors declare no conflicts of interest regarding the publication of this paper.

\section{References}

[1] Garg, R. (2001) Microstrip Antenna Design Handbook. Artech House, Norwood.

[2] Volakis, J. (2009) Antenna Engineering Handbook. McGraw-Hill, New York.

[3] Xu, F. and Wu, K. (2013) Understanding Leaky-Wave Structures: A Special Form of Guided-Wave Structure. IEEE Microwave Magazine, 14, 87-96.

[4] Goldstone, L. and Oliner, A.A. (1959) Leaky-Wave Antennas I: Rectangular Waveguides. IRE Transactions on Antennas and Propagation, 7, 307-319. https://doi.org/10.1109/TAP.1959.1144702

[5] Shokry, M.A. and Allam, A.M. (2017) Design of Uniform SIW Leaky Wave Antenna: With and without Supported Ground. Loughborough Antennas \& Propagation Conference, Loughborough, 14-15 November 2016, 1-5. https://doi.org/10.1109/LAPC.2016.7807473

[6] Xu, F. and Zhang, X. (2010) Periodic Leaky-Wave Antenna for Millimeter Wave Applications Based on Substrate Integrated Waveguide. IEEE Transactions on Antennas and Propagation, 58, 340-347. https://doi.org/10.1109/TAP.2009.2026593

[7] Gentile, G., Jovanović, V., Pelk, M.J., Jiang, L., Dekker, R., de Graaf, P., Rejaei, B., et al. (2013) Silicon-Filled Rectangular Waveguides and Frequency Scanning Antennas for mm-Wave Integrated Systems. IEEE Transactions on Antennas and Propagation, 61, 5893-5901. https://doi.org/10.1109/TAP.2013.2281518

[8] Mondal, P. and Wu, K. (2016) A Leaky-Wave Antenna Using Periodic Dielectric Perforation for Millimeter-Wave Applications. IEEE Transactions on Antennas and Propagation, 64, 5492-5495. https://doi.org/10.1109/TAP.2016.2621032

[9] Shaw, R. and Mandal, M.K. (2016) SIW Periodic Leaky Wave Antenna with Improved H-Plane Radiation Pattern Using Baffles. IEEE Indian Antenna Week, Madurai, 6-10 June 2016, 59-62. https://doi.org/10.1109/IndianAW.2016.7883598

[10] Hayashi, Y., Sakakibara, K., Nanjo, M., Sugawa, S., Kikuma, N. and Hirayama, H. (2011) Millimeter-Wave Microstrip Comb-Line Antenna Using Reflection-Canceling Slit Structure. IEEE Transactions on Antennas and Propagation, 59, 398-406. https://doi.org/10.1109/TAP.2010.2096180

[11] Mohammad-Ali-Nezhad, S. and Mallahzadeh, A. (2015) Periodic Ridged Leaky-Wave Antenna Design Based on SIW Technology. IEEE Antennas and Wireless Propagation Letters, 14, 354-357. https://doi.org/10.1109/LAWP.2014.2361175

[12] Gómez, J.L., Cañete, D. and Álvarez-Melcón, A. (2005) Printed-Circuit Leaky-Wave Antenna with Pointing and Illumination Flexibility. IEEE Microwave and Wireless 
Components Letters, 15, 536-538. https://doi.org/10.1109/LMWC.2005.852801

[13] Javanbakht, N., Syrett, B. and Amaya, R. (2018) Leaky-Wave Antenna Based on Modified Aperture Half-Mode Substrate Integrated Waveguide. IEEE International Symposium on Antennas and Propagation \& USNCI URSI National Radio Science Meeting, 14-21 July 2018, 1831-1832. https://doi.org/10.1109/APUSNCURSINRSM.2018.8608880

[14] Huang, S.-T. and Tseng, C.-H. (2017) Hand-Gesture Sensing Doppler Radar with Metamaterial-Based Leaky-Wave Antennas. IEEE MTT-S International Conference on Microwaves for Intelligent Mobility, Nagoya, 19-21 March 2017, 49-52. https://doi.org/10.1109/ICMIM.2017.7918853

[15] Gupta, S., Caloz, C. and Abielmona, S. (2008) CRLH Leaky-Wave Real-Time Spectrum Analyzer (RTSA) with Unrestricted Time-Frequency Resolution. IEEE MTT-S International Microwave Symposium Digest, Atlanta, 15-20 June 2008, 807-810. https://doi.org/10.1109/MWSYM.2008.4632955

[16] Mak, K.-M., So, K.-K., Lai, H.-W. and Luk, K.-M. (2017) A Magnetoelectric Dipole Leaky-Wave Antenna for Millimeter-Wave Application. IEEE Transactions on Antennas and Propagation, 65, 6395-6402. https://doi.org/10.1109/TAP.2017.2722868

[17] Martinez-Ros, A.J., Gomez-Tornero, J.L. and Goussetis, G. (2013) Holographic Pattern Synthesis with Modulated Substrate Integrated Waveguide Line-Source Leaky-Wave Antennas. IEEE Transactions on Antennas and Propagation, 61, 3466-3474. https://doi.org/10.1109/TAP.2013.2257650

[18] Eleftheriades, G.V., Iyer, A.K. and Kremer, P.C. (2002) Planar Negative Refractive Index Media Using Periodically L-C Loaded Transmission Lines. IEEE Transactions on Microwave Theory and Techniques, 50, 2702-2712. https://doi.org/10.1109/TMTT.2002.805197

[19] Lin, I.H., Caloz, C. and Itoh, T. (2002) Transmission Characteristics of Left Handed Non Uniform Transmission Lines. Proceedings of Asia-Pacific Microwave Conference, Kyoto, 19-22 November 2002, Vol. 3, 1501-1504.

[20] Caloz, C., Okabe, H., Iwai, H. and Itoh, T. (2002) Transmission Line Approach of Left-Handed Metamaterials. Proceedings of USNC/URSI National Radio Science Meeting, San Antonio, June 2002, 39.

[21] Oliner, A.A. (2002) A Periodic-Structure Negative-Refractive Index Medium without Resonant Elements. Proceedings of USNC/ URSI National Radio Science Meeting, San Antonio, June 2002, 41.

[22] Siddiqui, O.F., Mojahedi, M. and Eleftheriades, G.V. (2003) Periodically Loaded Transmission Line with Effective Negative Refractive Index and Negative Group Velocity. IEEE Transactions on Antennas and Propagation, 51, 2619-2625. https://doi.org/10.1109/TAP.2003.817556

[23] Eleftheriades, G.V., Siddiqui, O. and Iyer, A. (2003) Transmission Line Models for Negative Refractive Index Media and Associated Implementations without Excess Resonators. IEEE Microwave and Wireless Components Letters, 13, 53-55. https://doi.org/10.1109/LMWC.2003.808719

[24] Baena, J.D., Bonache, J., Martın, F., Marques, R., Falcone, F., Lopetegi, T., Laso, M.A.G., Garcia, J., Gil, I. and Sorolla, M. (2005) Equivalent Circuit Models for Split Ring Resonators and Complementary Split Rings Resonators Coupled to Planar Transmission Lines. IEEE Transactions on Microwave Theory and Techniques, 53, 1451-1461. https://doi.org/10.1109/TMTT.2005.845211

[25] Bahl, I. and Bhartia, P. (1988) Microwave Solid State Circuit Design. Wiley, Toronto. 
[26] Caloz, C. and Itoh, T. (2006) Electromagnetic Metamaterials: Transmission Line Theory and Microwave Applications. Chapter 6, John Wiley \& Sons Inc., Hoboken.

[27] Lai, A., Itoh, T. and Caloz, C. (2004) Composite Right/Left-Handed Transmission Line Metamaterials. IEEE Microwave Magazine, 5, 34-50.

https://doi.org/10.1109/MMW.2004.1337766 